\title{
COMPARISON BETWEEN SOME METEOROLOGICAL ELEMENTS MEASURED BY ECMWF AND EARTH STATIONS IN DIFFERENT REGIONS IN IRAQ
}

\author{
Rajaa A. Basheer $\bowtie$ \\ Department of Physics \\ College of Education \\ University of Al-Hamdaniya \\ Erbil road, Al-Hamdaniya District, Nineveh, Iraq, 41006 \\ ragaa.habsh@uohamdaniya.edu.iq \\ Waleed I. AL-Rijabo \\ Department of Physics \\ College of Education of Pure Science \\ Mosul University \\ Mosul, Iraq
}

$\triangle$ Corresponding author

\begin{abstract}
The aim of this paper is to validate the data of three meteorological elements Air Temperature (Ta), Relative Humidity (RH), Wind Speed (WS) from the European Center For-Medium Range Weather Forecasting (ECMWF), against ground stations data using several Models at six stations well distributed in Iraq (Mosul, Kirkuk, Baghdad, Kut, Nasiriya, and Basra).

Due to the difficulties which experienced by the ground climate stations in Iraq from a shortage of devices and equipment for measuring the various climatic elements, which led to a huge shortage of data throughout time for political, economic and natural disasters. It is found that researchers can adopt the data of satellite stations to monitor the climate because let's found that there is a highly significance Correlations between the data of these stations and the data of the ground stations for climate monitoring

Five Mathematical Models were used for that [Linear Models, Quadratic Models, Exponential Models, Logarithmic Models, and Power Models]. The performance of these models were evaluated by comparing the calculated (Ta, RH, WS) from earth stations.

Those mathematical correlations help to be able to calculate the ground data in state of there is no ground climate stations data.

Several statistical tests Correlation Coefficient $(R)$, Coefficient of Determination $\left(R^{2}\right)$, Root Mean Square Error (RMSE), Mean Absolute Error (MAE) were used to control the validation and goodness of these Models.

The $R^{2}$ obtained from these Models were very high in all stations. This means that, there is a highly significance Correlations between (Ta, RH, WS) estimated and [Ta, RH, WS] measured in all station.

Keywords: ECMWF, NASA, Regression Models, atmosphere, weather forecast, IRAQ, Root Mean Square Error, Mean Absolute Error, Earth observation, satellite.
\end{abstract}

DOI: $10.21303 / 2461-4262.2021 .001941$

\section{Introduction}

Weather forecast satellite caused a huge impact in the field of atmospheric observation and weather forecast. This is a result of providing it with big amount of data, maps, and images about the element of atmospheric phenomena and weather [1].

ERA5 is the latest version of climate reanalysis, which was produced by the European Center For-Range Weather Forecasting (ECMWF), to provide monthly data on many atmospheric, land and sea-state parameters together. ECMWF operational forecasts aim to show how the weather is most likely to evolve [2].

Satellite data are very useful in various applications like astronomy, atmospheric studies, earth observation, communications, navigation, search and rescue [3].

Dedicated centers such as ECMWF and The National Aeronautics and Space Administration (NASA) collect and provide data for climate studies, weather forecasting and other purposes [4]. Let's choose the use of ECMWF databases that have been tried and tested elsewhere [5]. 
Researches around the world investigated empirical and statistical Models which consist a simple Regression between satellite measurements and corresponding measurement at the earth surface [6].

Ground observations suffer from two draw backs, which are: firstly the ground observation networks are expensive to maintain for extended period of times, secondly, the ground observations are point observations and thereby do not capture the spatial variability over large regions. Satellite database overcome on those two drawbacks [7]. Most of the satellite sensors are fixed in the orbit for multiple years and are repeating observation 2-4 times of day from the land surface [8].

Land surface temperature is an important parameter in the field of atmospheric sciences as it combines the results of all surfaces. Atmosphere interaction and energy flux between the ground and the atmosphere [9]. Relative Humidity measurement is the more commonly used in the research concerning the determinants of pathogen survivals and transmission [10].

As atmospheric has big effect on the wind speed and other parameters in the atmosphere thus this parameter has huge correlations with those parameters, so that it has the big importance in weather predictions [11].

Regression Models were used to validate the data of (Ta, RH, WS) from ECMWF against ground station data in six well stations which are distributed in Iraq (Mosul, Kirkuk, Baghdad, Kut, Nasiriya, and Basra).

\section{Materials and methods}

Table 1 which shows the geographical coordinate of all stations and Fig. 1 show the locations of these stations in Iraq.

Table 1

Geographical coordinates of all stations

\begin{tabular}{cccc}
\hline Stations & Latitude & Longitude & Altitude (m) \\
\hline Mosul & $36.32^{\circ}$ & $43.15^{\circ}$ & 223 \\
Kirkuk & $35.47^{\circ}$ & $44.40^{\circ}$ & 331 \\
Baghdad & $33.30^{\circ}$ & $44.23^{\circ}$ & 32 \\
Kut & $32.42^{\circ}$ & $44.75^{\circ}$ & 19 \\
Nasiriya & $31.08^{\circ}$ & $46.23^{\circ}$ & 3 \\
Basra & $30.52^{\circ}$ & $47.61^{\circ}$ & 2
\end{tabular}

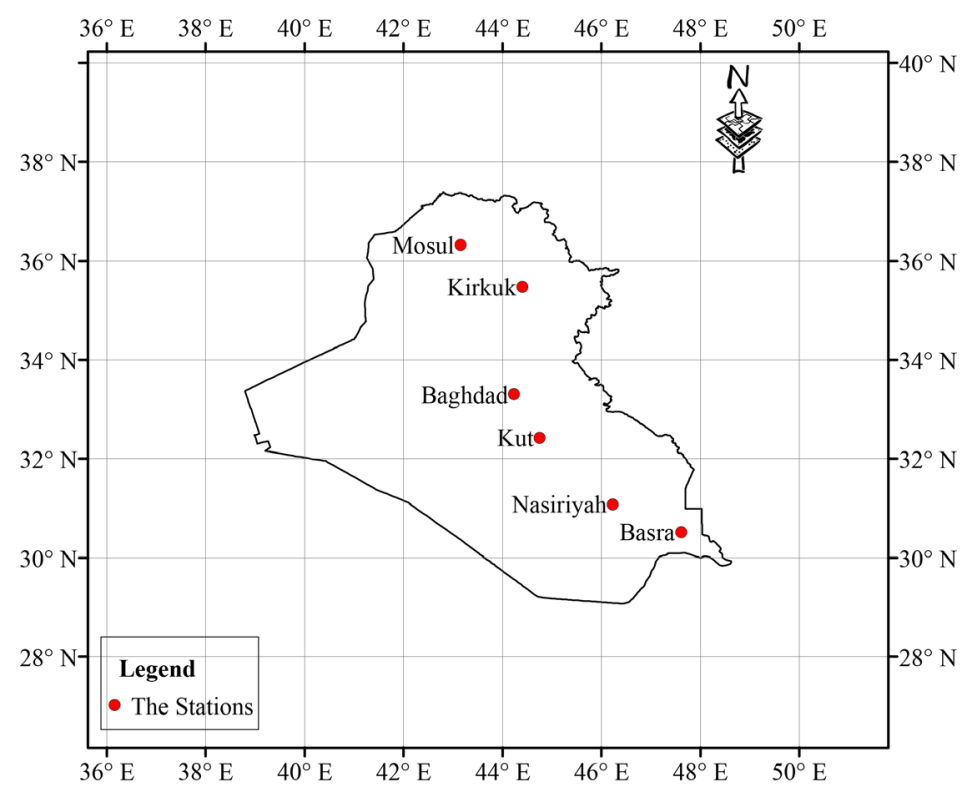

Fig. 1. The locations of all stations in Iraq 
The estimated data of Air Temperature, Relative Humidity and Wind speed were obtained from European Center for Medium - range Weather Forecasting (ECMWF) for Six meteorological stations (Mosul, Kirkuk, Baghdad, Kut, Nasiriya, and Basra) wells that are distributed in Iraq for the period (1995-2018).

The Measured data (Ta, RH, WS) for the different stations were obtained from Iraqi Meteorological Organization for the same periods. Tables 2-4 show the estimated and measured values of (Ta, RH, WS).

Table 2

Mean air temperature at $2 \mathrm{~m}$ in all stations

\begin{tabular}{|c|c|c|c|c|c|c|c|c|c|c|c|c|}
\hline Months & Jan. & Feb. & Mar. & Apr. & May & Jun. & Jul. & Aug. & Sep. & Oct. & Nov. & Dec. \\
\hline \multicolumn{13}{|c|}{ Mosul } \\
\hline T ECMWF & 7.4 & 9.3 & 13.4 & 18.6 & 25.3 & 31.7 & 35.1 & 34.3 & 29.2 & 22.8 & 14.6 & 9.3 \\
\hline T station & 7 & 8.6 & 12.6 & 17.9 & 24.7 & 30.8 & 34.5 & 33.7 & 28.5 & 22.4 & 13.7 & 9 \\
\hline \multicolumn{13}{|c|}{ Kirkuk } \\
\hline T ECMWF & 8.9 & 11.0 & 15.5 & 21.2 & 27.9 & 33.5 & 36.6 & 36.0 & 31.0 & 24.7 & 16.0 & 10.8 \\
\hline T station & 9 & 10.5 & 14.8 & 20.7 & 27.6 & 33.3 & 36.2 & 35.6 & 31.2 & 24.8 & 16.3 & 10.9 \\
\hline \multicolumn{13}{|c|}{ Baghdad } \\
\hline T ECMWF & 11.0 & 13.6 & 18.7 & 24.6 & 30.8 & 35.4 & 37.8 & 37.5 & 33.1 & 26.9 & 17.8 & 12.6 \\
\hline T station & 10.1 & 13.0 & 17.5 & 23.4 & 29.7 & 33.5 & 35.9 & 35.5 & 31.1 & 25.1 & 16.5 & 11.8 \\
\hline \multicolumn{13}{|c|}{ Kut } \\
\hline T ECMWF & 12.2 & 14.9 & 20.2 & 26.1 & 32.4 & 36.8 & 39.0 & 38.9 & 34.6 & 28.4 & 19.0 & 13.8 \\
\hline T station & 11.0 & 13.1 & 17.4 & 24.3 & 30.5 & 34.7 & 36.7 & 35.8 & 32.0 & 26.0 & 18.1 & 12.8 \\
\hline \multicolumn{13}{|c|}{ Nasiriya } \\
\hline T ECMWF & 12.6 & 15.6 & 20.9 & 26.9 & 33.5 & 37.6 & 39.5 & 39.4 & 35.1 & 28.7 & 19.5 & 14.1 \\
\hline T station & 12.3 & 15.3 & 20.5 & 25.8 & 32.7 & 36.6 & 37.8 & 38.3 & 34.1 & 28.4 & 19.3 & 13.9 \\
\hline \multicolumn{13}{|c|}{ Basra } \\
\hline T ECMWF & 13.1 & 16.0 & 21.0 & 27.2 & 33.9 & 38.1 & 39.8 & 39.5 & 35.2 & 28.9 & 20.0 & 14.7 \\
\hline T station & 12.3 & 14.6 & 19.4 & 26.1 & 32.4 & 36.1 & 37.8 & 37.2 & 33.6 & 27.8 & 19.8 & 14 \\
\hline
\end{tabular}

Table 3

Relative Humidity \% in all stations

\begin{tabular}{|c|c|c|c|c|c|c|c|c|c|c|c|c|}
\hline Months & Jan. & Feb. & Mar. & Apr. & May. & Jun. & Jul. & Aug. & Sep. & Oct. & Nov. & Dec. \\
\hline \multicolumn{13}{|c|}{ Mosul } \\
\hline RH ECMWF & 77 & 74 & 65 & 55 & 40 & 24 & 21 & 22 & 28 & 43 & 65 & 74 \\
\hline RH station & 77 & 72 & 65 & 60 & 42 & 28 & 25 & 27 & 32 & 45 & 62 & 75 \\
\hline \multicolumn{13}{|c|}{ Kirkuk } \\
\hline RH ECMWF & 74 & 70 & 59 & 49 & 34 & 21 & 19 & 20 & 25 & 39 & 60 & 72 \\
\hline RH station & 73 & 66 & 57 & 50 & 34 & 24 & 23 & 25 & 29 & 40 & 56 & 67 \\
\hline \multicolumn{13}{|c|}{ Baghdad } \\
\hline RH ECMWF & 63 & 56 & 45 & 39 & 28 & 20 & 19 & 21 & 24 & 31 & 49 & 58 \\
\hline RH station & 68 & 57 & 47 & 40 & 31 & 25 & 24 & 26 & 31 & 41 & 59 & 67 \\
\hline \multicolumn{13}{|c|}{ Kut } \\
\hline RH ECMWF & 61 & 54 & 42 & 38 & 27 & 20 & 20 & 21 & 24 & 29 & 46 & 56 \\
\hline RH & 71 & 62 & 54 & 44 & 32 & 24 & 23 & 24 & 28 & 39 & 58 & 70 \\
\hline \multicolumn{13}{|c|}{ Nasiriya } \\
\hline RH ECMWF & 60 & 51 & 40 & 35 & 23 & 17 & 17 & 18 & 20 & 27 & 45 & 56 \\
\hline RH station & 65 & 56 & 46 & 40 & 29 & 21 & 20 & 22 & 26 & 36 & 53 & 64 \\
\hline \multicolumn{13}{|c|}{ Basra } \\
\hline RH ECMWF & 64 & 55 & 43 & 36 & 23 & 16 & 17 & 20 & 23 & 35 & 53 & 61 \\
\hline RH station & 66 & 56 & 45 & 39 & 27 & 20 & 22 & 24 & 27 & 38 & 53 & 65 \\
\hline
\end{tabular}


Table 4

Wind Speed $(\mathrm{m} / \mathrm{s})$ near earth surface in all stations

\begin{tabular}{|c|c|c|c|c|c|c|c|c|c|c|c|c|}
\hline Months & Jan. & Feb. & Mar. & Apr. & May. & Jun. & Jul. & Aug. & Sep. & Oct. & Nov. & Dec. \\
\hline \multicolumn{13}{|c|}{ Mosul } \\
\hline WS ECMWF & 2.0 & 2.0 & 2.2 & 2.4 & 2.5 & 2.6 & 2.6 & 2.4 & 2.2 & 2.1 & 1.9 & 1.9 \\
\hline WS station & 1.2 & 1.3 & 1.4 & 1.7 & 1.8 & 1.7 & 1.7 & 1.6 & 1.4 & 1.1 & 0.9 & 1.2 \\
\hline \multicolumn{13}{|c|}{ Kirkuk } \\
\hline WS ECMWF & 2.6 & 2.7 & 2.9 & 3.0 & 3.2 & 3.3 & 3.2 & 3.1 & 2.8 & 2.8 & 2.5 & 2.5 \\
\hline WS station & 1.6 & 1.9 & 2 & 2.1 & 2.2 & 2.1 & 2.1 & 1.8 & 1.6 & 1.6 & 1.4 & 1.4 \\
\hline \multicolumn{13}{|c|}{ Baghdad } \\
\hline WS ECMWF & 2.9 & 3.2 & 3.5 & 3.6 & 3.8 & 4.7 & 4.9 & 4.4 & 3.7 & 3.2 & 2.9 & 2.9 \\
\hline WS station & 2.6 & 2.8 & 3.2 & 3.3 & 3.2 & 3.8 & 3.8 & 3.4 & 2.9 & 2.7 & 2.3 & 2.5 \\
\hline \multicolumn{13}{|c|}{ Kut } \\
\hline WS ECMWF & 3.1 & 3.4 & 3.6 & 3.7 & 3.9 & 4.8 & 5.0 & 4.6 & 3.9 & 3.3 & 3.0 & 3.0 \\
\hline WS station & 3.4 & 3.7 & 3.9 & 3.8 & 4.1 & 5.8 & 6.2 & 5.5 & 4.3 & 3.5 & 3.4 & 3.3 \\
\hline \multicolumn{13}{|c|}{ Nasiriya } \\
\hline WS ECMWF & 3.8 & 4.1 & 4.3 & 4.4 & 4.6 & 6.1 & 6.2 & 5.7 & 4.9 & 4.0 & 3.6 & 3.6 \\
\hline WS station & 3.3 & 3.8 & 4.2 & 4.5 & 4.7 & 6 & 6 & 5.2 & 4.1 & 3.4 & 3.3 & 3.2 \\
\hline \multicolumn{13}{|c|}{ Basra } \\
\hline WS ECMWF & 3.7 & 4.1 & 4.2 & 4.3 & 4.4 & 5.9 & 5.8 & 5.2 & 4.7 & 3.8 & 3.6 & 3.6 \\
\hline WS station & 3.8 & 4 & 4.4 & 4.4 & 4.2 & 5.6 & 5.3 & 4.7 & 4.2 & 3.4 & 3.2 & 3.3 \\
\hline
\end{tabular}

Five mathematical Models (Exponential, Linear, Logarithmic, Quadratic, and Power) were used to test the Correlation between the estimated and measured values of (Ta, RH, WS) in the six stations. Mean Absolute Error (M.A.E.), Root Mean Square Error (RMSE), coefficient of determination $\left(R^{2}\right)$, and the Correlation Coefficient $(R)$ were used for the purpose of evaluating the results.

\section{Results and discussion}

Five Mathematical Models were used to test the Correlations between (T ECMWF, RH ECMWF, and WS ECMWF) and (T stat., RH stat., and WS stat.) data in (Mosul, Kirkuk, Baghdad, Kut, Nasiriya, and Basra) stations. From these Models let's choose the Model which give the highest $R^{2}$. Fig. 2-4 show the Correlations between (Ta ECMWF \& Ta stat.), (RH ECMWF \& RH stat.), (WS ECMWF \& WS stat.) in all stations.

Table 5 show the Models with Regression and Statistical Indicator for all stations.

From Table $\mathbf{5}$ it is possible to see:

- for air temperature:

A highly acceptable Correlations for these models were obtained between (Ta ECMWF\&Ta stat.) in all stations with $R^{2}$ were ranged between $(0.996-0.999)$. It is also possible to that the (MAE) for these Models in all stations were ranged between (0.78-3.14) \% indicating an excellent fitting between (Ta ECMWF\&Ta stat.). The (RMSE) for these Regression Correlations in all stations was ranged between (1.39-4.90) \% which also show a good performance. Linear Model give the best all stations except in Nasiriya stations where Quadratic Model give the best fit;

- for relative humidity:

Linear Model give the best fit in Kirkuk station when $R^{2}=0.994$. Power Model gave the fit in Mosul station with $R^{2}=995$. Quadratic Model gave the best fit between (RH ECMWF \& RH stat.) in Kut, Nasiriya, and Basra stations where $R^{2}$ range between (0.987-0.997).

The MAE for these Correlations in all stations ranged between (3.66-8.39) \% while the RMSE Ranged between (6.78-12.2) \% for all stations, which mean that these Models gave an excellent fitting between (RH ECMWF \& RH stat.);

- for wind speed:

Linear Model gave the best fit in Mosul, Kirkuk, Kut stations, where $R^{2}$ equal $(0.848,0.752,0.966)$ for these stations respectively. 
Quadratic Model gave the best fit in Baghdad station where $R^{2}=(0.903)$. Logarithmic Model gave the best fit in Nasiriya and Basra stations. Where $R^{2}$ equal to $(0.924,0.925)$.

The MAE in all stations ranged between (3.37-30.36) \%, while the RMSE ranged between (5.16-44.9) \%. This mean that a good Correlations was obtained between (WS ECMWF\&WS stat.) in all stations.

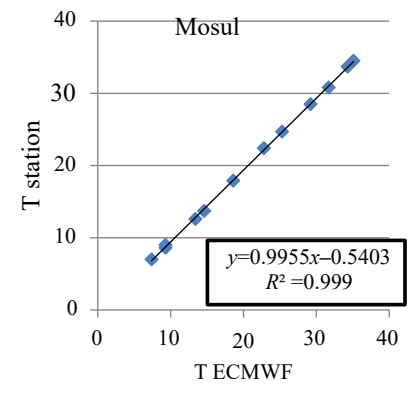

$a$

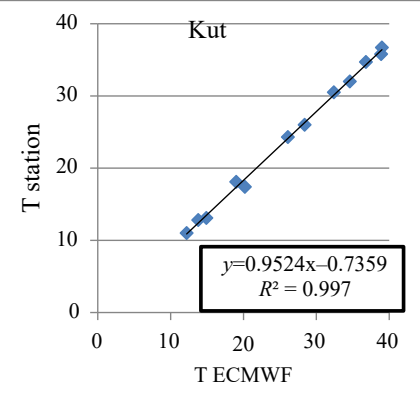

d

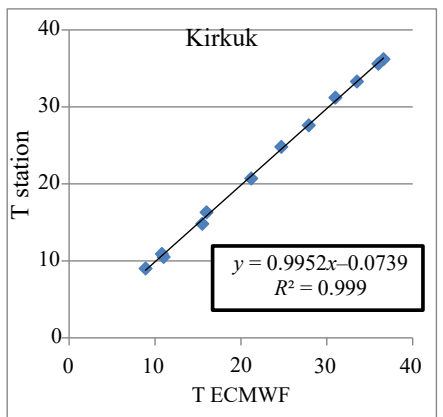

$b$

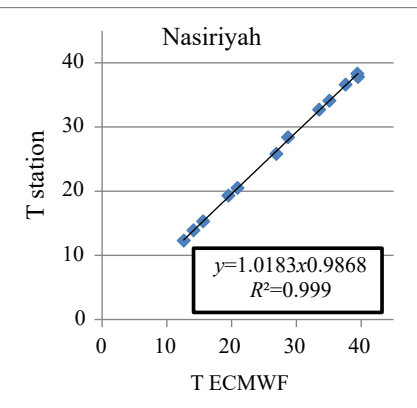

e

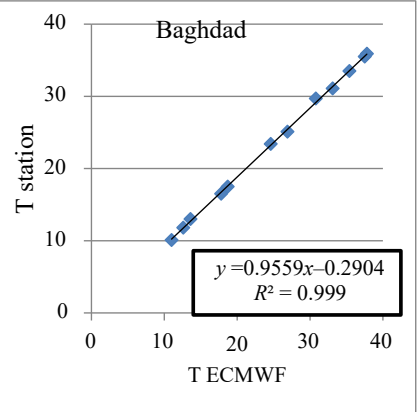

c

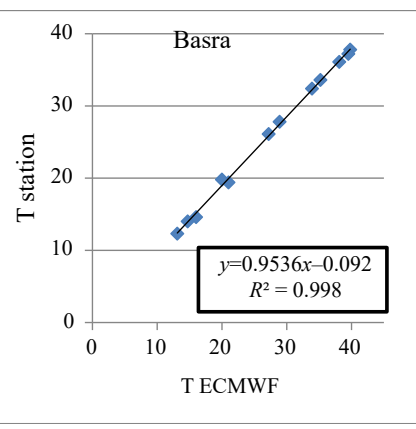

$f$

Fig. 2. Correlations between $\mathrm{T}$ station \& $\mathrm{T}$ ECMWF in $\left(\mathrm{C}^{\circ}\right): a-$ Mosul; $b-$ Kirkuk; $c$-Baghdad; $d$-Kut; $e$ - Nasiriyah; $f$-Basra
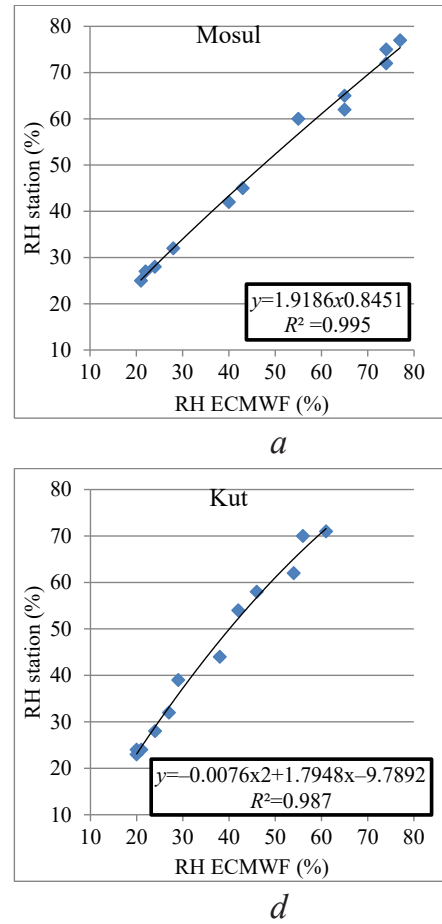

Fig. 3. Correlations between RH sta. \& RH sat.: $a$ - Mosul; $b$ - Kirkuk; $c$ - Baghdad; $d$-Kut; $e$-Nasiriyah; $f$-Basra
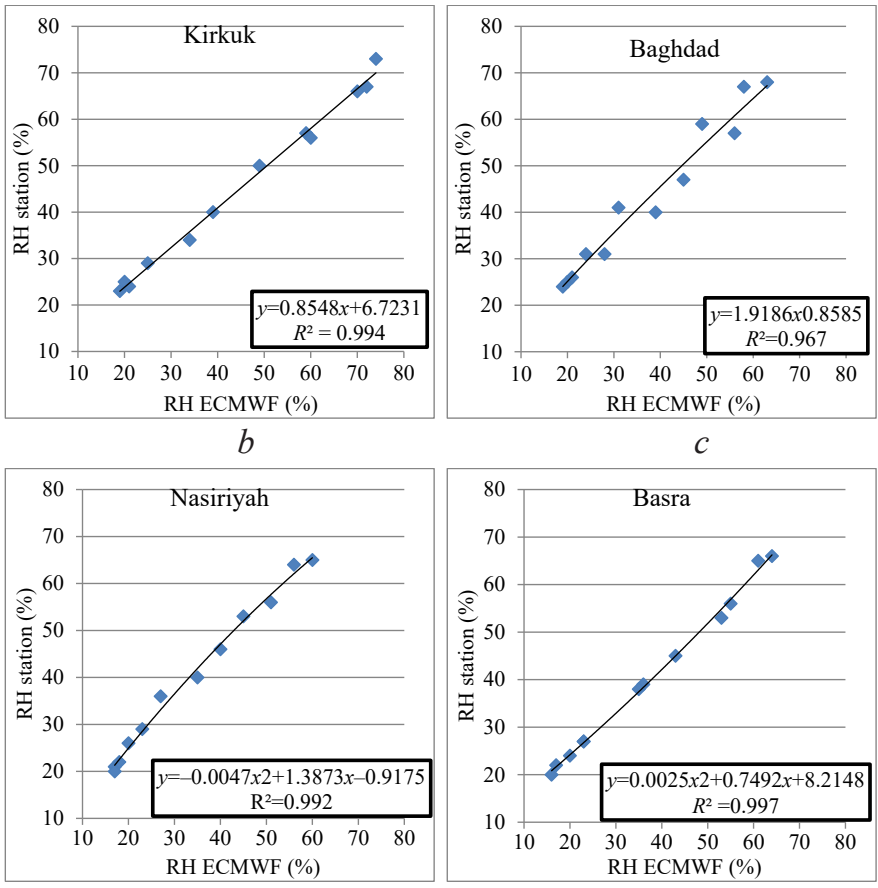

$f$ 

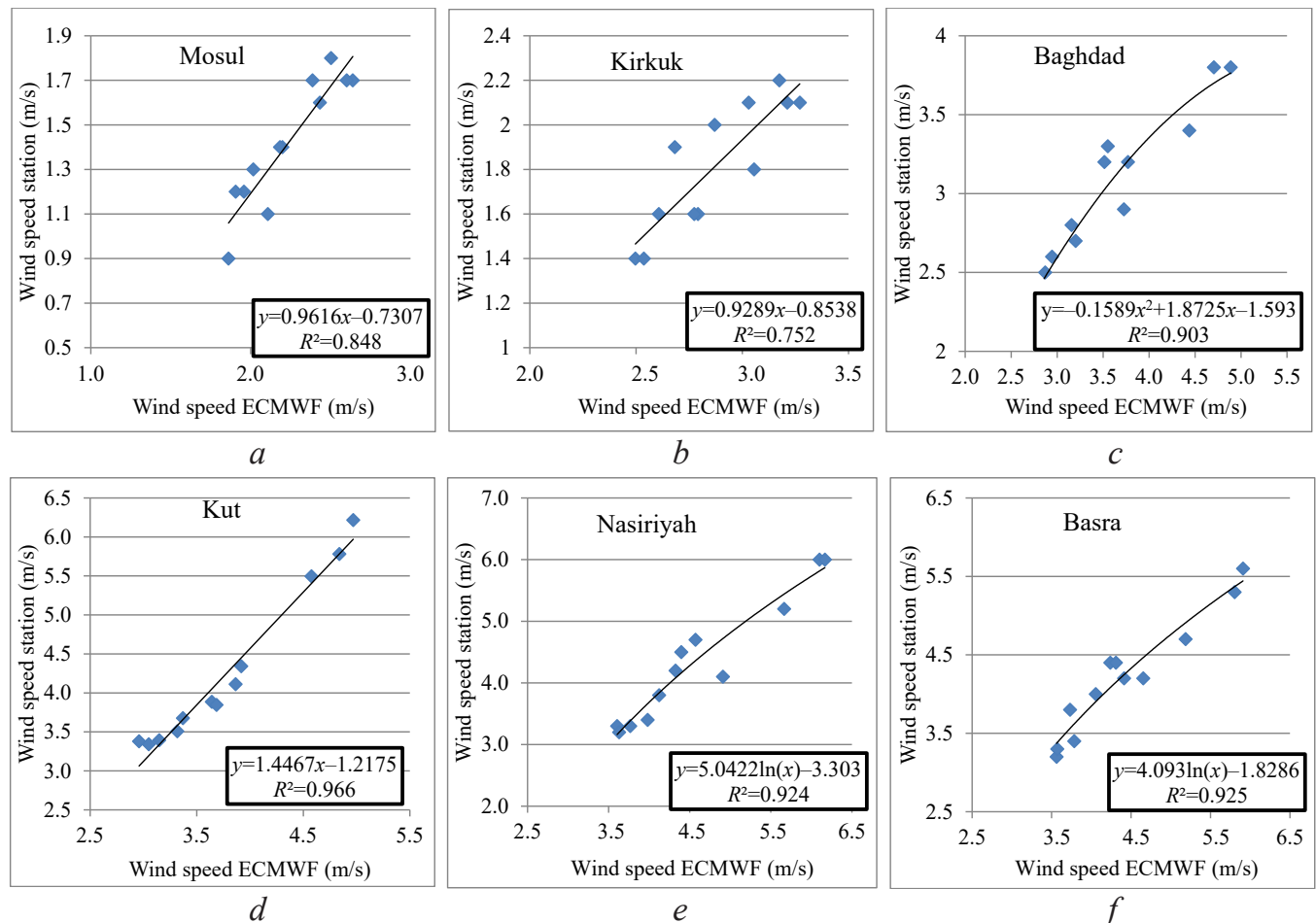

Fig. 4. Correlations between WS sta. \&WS sat.: $a$-Mosul; $b$ - Kirkuk; $c$ - Baghdad;

$d$-Kut; $e$-Nasiriyah; $f$ - Basra

Table 5

Models with Regression and statistical indicator for all Stations

\begin{tabular}{|c|c|c|c|c|c|}
\hline Stations & Correlations & $R^{2}$ & $\boldsymbol{R}$ & $\%$ MAE & $\%$ RMSE \\
\hline Mosul & T sta. $=0.9955$ T sat. -0.5403 & 0.999 & 0.999 & 1.96 & 3.15 \\
\hline Kirkuk & T sta. $=0.9952 \mathrm{~T}$ sat. -0.0739 & 0.999 & 0.999 & 0.86 & 1.59 \\
\hline Baghdad & $\mathrm{T}$ sta. $=0.9559 \mathrm{~T}$ sat. -0.2904 & 0.999 & 0.999 & 3.09 & 4.47 \\
\hline Kut & $\mathrm{T}$ sta. $=0.9524 \mathrm{~T}$ sat. -0.7359 & 0.997 & 0.998 & 4.40 & 6.61 \\
\hline Nasiriya & $\mathrm{T}$ sta. $=1.0183 \mathrm{~T}$ sat. ${ }^{0.9868}$ & 0.999 & 0.999 & 1.23 & 1.90 \\
\hline Basra & $\mathrm{T}$ sta. $=0.9536 \mathrm{~T}$ sat. -0.092 & 0.998 & 0.998 & 2.71 & 4.10 \\
\hline Mosul & $\mathrm{RH}$ sta. $=1.9186 \mathrm{RH}$ sat..$^{0.8451}$ & 0.995 & 0.998 & 3.66 & 6.78 \\
\hline Kirkuk & RH sta. $=0.8548$ RH sat. +6.7231 & 0.994 & 0.997 & 3.91 & 7.12 \\
\hline Baghdad & $\mathrm{RH}$ sta. $=1.9186 \mathrm{RH}$ sat. ${ }^{0.8585}$ & 0.967 & 0.983 & 6.79 & 11.09 \\
\hline Kut & RH sta. $=-0.0076 \mathrm{RH}$ sat. ${ }^{2}+1.7948 \mathrm{RH}$ sat. -9.7892 & 0.987 & 0.993 & 8.39 & 12.22 \\
\hline Nasiriya & $\mathrm{RH}$ sta. $=-0.0047 \mathrm{RH}$ sat. ${ }^{2}+1.3873 \mathrm{RH}$ sat. -0.9175 & 0.996 & 0.996 & 7.95 & 11.82 \\
\hline Basra & $\mathrm{RH}$ sta. $=0.0025 \mathrm{RH}$ sat $^{2}+0.7492 \mathrm{RH}$ sat. +8.2148 & 0.997 & 0.998 & 5.00 & 8.72 \\
\hline Mosul & WS sta. $=0.9616$ WS sat. -0.7307 & 0.848 & 0.920 & 30.36 & 44.93 \\
\hline Kirkuk & WS sta. $=0.9289$ WS sat. -0.8538 & 0.752 & 0.867 & 30.08 & 43.73 \\
\hline Baghdad & WS sta. $=-0.1589$ WS sat. $2+1.8725$ WS sat. -1.593 & 0.903 & 0.950 & 9.60 & 14.57 \\
\hline Kut & WS sta. $=1.4467$ WS sat. -1.2175 & 0.966 & 0.983 & 5.06 & 7.96 \\
\hline Nasiriya & WS sta. $=5.0422 \ln ($ WS sat.) -3.303 & 0.924 & 0.961 & 4.32 & 7.45 \\
\hline Basra & WS sta. $=4.093 \ln ($ WS sat.) -1.8286 & 0.925 & 0.962 & 3.37 & 5.14 \\
\hline
\end{tabular}


Table 6

Show a comparison between ( $\mathrm{T}, \mathrm{RH}$, and WS) estimated from the Models and (T, RH, and WS) measured for all stations

\begin{tabular}{|c|c|c|c|c|c|c|c|c|c|c|c|c|}
\hline \multirow{2}{*}{ Months } & \multicolumn{2}{|c|}{ Mosul } & \multicolumn{2}{|c|}{ Kirkuk } & \multicolumn{2}{|c|}{ Baghdad } & \multicolumn{2}{|c|}{ Kut } & \multicolumn{2}{|c|}{ Nasiriya } & \multicolumn{2}{|c|}{ Basra } \\
\hline & T est. & T mea. & T est. & T mea. & T est. & T mea. & T est. & T mea. & T est. & T mea. & T est. & T mea. \\
\hline Jan. & 6.4 & 7 & 8.9 & 9 & 9.4 & 10.1 & 9.7 & 11 & 12.1 & 12.3 & 11.6 & 12.3 \\
\hline Feb. & 8.0 & 8.6 & 10.4 & 10.5 & 12.1 & 13 & 11.7 & 13.1 & 15.0 & 15.3 & 13.8 & 14.6 \\
\hline Mar. & 12.0 & 12.6 & 14.7 & 14.8 & 16.4 & 17.5 & 15.8 & 17.4 & 20.1 & 20.5 & 18.4 & 19.4 \\
\hline Apr. & 17.3 & 17.9 & 20.5 & 20.7 & 22.1 & 23.4 & 22.4 & 24.3 & 25.2 & 25.8 & 24.8 & 26.1 \\
\hline May & 24.0 & 24.7 & 27.4 & 27.6 & 28.1 & 29.7 & 28.3 & 30.5 & 31.8 & 32.7 & 30.8 & 32.4 \\
\hline Jun. & 30.1 & 30.8 & 33.1 & 33.3 & 31.7 & 33.5 & 32.3 & 34.7 & 35.5 & 36.6 & 34.3 & 36.1 \\
\hline Jul. & 33.8 & 34.5 & 36.0 & 36.2 & 34.0 & 35.9 & 34.2 & 36.7 & 36.7 & 37.8 & 36.0 & 37.8 \\
\hline Aug. & 33.0 & 33.7 & 35.4 & 35.6 & 33.6 & 35.5 & 33.4 & 35.8 & 37.2 & 38.3 & 35.4 & 37.2 \\
\hline Sep. & 27.8 & 28.5 & 31.0 & 31.2 & 29.4 & 31.1 & 29.7 & 32 & 33.1 & 34.1 & 31.9 & 33.6 \\
\hline Oct. & 21.8 & 22.4 & 24.6 & 24.8 & 23.7 & 25.1 & 24.0 & 26 & 27.7 & 28.4 & 26.4 & 27.8 \\
\hline Nov. & 13.1 & 13.7 & 16.1 & 16.3 & 15.5 & 16.5 & 16.5 & 18.1 & 18.9 & 19.3 & 18.8 & 19.8 \\
\hline Dec. & 8.4 & 9 & 10.8 & 10.9 & 11.0 & 11.8 & 11.5 & 12.8 & 13.7 & 13.9 & 13.3 & 14 \\
\hline & \multicolumn{2}{|c|}{ Mosul } & \multicolumn{2}{|c|}{ Kirkuk } & \multicolumn{2}{|c|}{ Baghdad } & \multicolumn{2}{|c|}{ Kut } & \multicolumn{2}{|c|}{ Nasiriya } & \multicolumn{2}{|c|}{ Basra } \\
\hline
\end{tabular}

Months RH est. RH mea. RH est. RH mea. RH est. RH mea. RH est. RH mea. RH est. RH mea. RH est. RH mea.

\begin{tabular}{|c|c|c|c|c|c|c|c|c|c|c|c|c|}
\hline Jan. & 75 & 77 & 69 & 73 & 72 & 68 & 79 & 71 & 69 & 65 & 69 & 66 \\
\hline Feb. & 71 & 72 & 63 & 66 & 62 & 57 & 72 & 62 & 62 & 56 & 58 & 56 \\
\hline Mar. & 65 & 65 & 55 & 57 & 52 & 47 & 65 & 54 & 53 & 46 & 47 & 45 \\
\hline Apr. & 61 & 60 & 49 & 50 & 46 & 40 & 54 & 44 & 47 & 40 & 41 & 39 \\
\hline May & 45 & 42 & 36 & 34 & 37 & 31 & 40 & 32 & 35 & 29 & 30 & 27 \\
\hline Jun. & 32 & 28 & 27 & 24 & 30 & 25 & 29 & 24 & 26 & 21 & 24 & 20 \\
\hline Jul. & 29 & 25 & 26 & 23 & 29 & 24 & 27 & 23 & 25 & 20 & 26 & 22 \\
\hline Aug. & 31 & 27 & 28 & 25 & 31 & 26 & 29 & 24 & 27 & 22 & 28 & 24 \\
\hline Sep. & 36 & 32 & 32 & 29 & 37 & 31 & 35 & 28 & 32 & 26 & 30 & 27 \\
\hline Oct. & 48 & 45 & 41 & 40 & 47 & 41 & 49 & 39 & 43 & 36 & 40 & 38 \\
\hline Nov. & 63 & 62 & 55 & 56 & 64 & 59 & 69 & 58 & 59 & 53 & 55 & 53 \\
\hline Dec. & 74 & 75 & 64 & 67 & 71 & 67 & 79 & 70 & 69 & 64 & 67 & 65 \\
\hline \multirow{2}{*}{ Months } & \multicolumn{2}{|c|}{ Mosul } & \multicolumn{2}{|c|}{ Kirkuk } & \multicolumn{2}{|c|}{ Baghdad } & \multicolumn{2}{|c|}{ Kut } & \multicolumn{2}{|c|}{ Nasiriya } & \multicolumn{2}{|c|}{ Basra } \\
\hline & WS est. & WS mea. & WS est. & WS mea. & WS est. & WS mea. & WS est. & WS mea. & WS est. & WS mea. & WS est. & WS mea. \\
\hline Jan. & 0.4 & 1.2 & 0.6 & 1.6 & 2.2 & 2.6 & 3.7 & 3.4 & 2.7 & 3.3 & 3.6 & 3.8 \\
\hline Feb. & 0.5 & 1.3 & 0.9 & 1.9 & 2.4 & 2.8 & 4.1 & 3.7 & 3.4 & 3.8 & 3.8 & 4 \\
\hline Mar. & 0.6 & 1.4 & 1.0 & 2 & 2.8 & 3.2 & 4.4 & 3.9 & 3.9 & 4.2 & 4.2 & 4.4 \\
\hline Apr. & 0.9 & 1.7 & 1.1 & 2.1 & 2.9 & 3.3 & 4.3 & 3.8 & 4.3 & 4.5 & 4.2 & 4.4 \\
\hline May & 1.0 & 1.8 & 1.2 & 2.2 & 2.8 & 3.2 & 4.7 & 4.1 & 4.5 & 4.7 & 4.0 & 4.2 \\
\hline Jun. & 0.9 & 1.7 & 1.1 & 2.1 & 3.2 & 3.8 & 7.1 & 5.8 & 5.7 & 6.0 & 5.2 & 5.6 \\
\hline Jul. & 0.9 & 1.7 & 1.1 & 2.1 & 3.2 & 3.8 & 7.8 & 6.2 & 5.7 & 6.0 & 5.0 & 5.3 \\
\hline Aug. & 0.8 & 1.6 & 0.8 & 1.8 & 2.9 & 3.4 & 6.7 & 5.5 & 5.0 & 5.2 & 4.5 & 4.7 \\
\hline Sep. & 0.6 & 1.4 & 0.6 & 1.6 & 2.5 & 2.9 & 5.1 & 4.3 & 3.8 & 4.1 & 4.0 & 4.2 \\
\hline Oct. & 0.3 & 1.1 & 0.6 & 1.6 & 2.3 & 2.7 & 3.9 & 3.5 & 2.9 & 3.4 & 3.2 & 3.4 \\
\hline Nov. & 0.1 & 0.9 & 0.4 & 1.4 & 1.9 & 2.3 & 3.7 & 3.4 & 2.7 & 3.3 & 2.9 & 3.2 \\
\hline Dec. & 0.4 & 1.2 & 0.4 & 1.4 & 2.1 & 2.5 & 3.6 & 3.3 & 2.6 & 3.2 & 3.1 & 3.3 \\
\hline
\end{tabular}




\section{Discussion of the Data.}

For air temperature it is possible to see from the Table 6 that the estimated values of Ta from the Models and measured values is nearly equal, this mean that there is an excellent agreement between the estimated and measured values of (Ta) in all stations.

For relative humidity it is possible to see also from Table 6 that there is a good agreement between the estimated value of (RH) by the Models and the measured values in all stations.

For wind speed it is possible to see for Baghdad, Kut, Nasiriyah, and Basra stations that there is a good agreement between the estimated values of wind speed from the Models and the measured values.

For Mosul and Kirkuk stations a good agreement between the estimated and measured values of (WS) are not obtained, this is due to high difference between WS-ECMWF and WS-Stations in Mosul and Kirkuk stations.

The study arrives to these results after adopting Mathematical and Statistical method used to analyze the results. The results reflect the essence of the exigency of manipulating a private schematic comparison between the new discovered results and those registered previously in order to understand the reasons and motivations behind such differences.

The major features of the proposed method and the results obtained in comparison to the existed ones are: Firstly, choosing different Earth stations which covers Iraq's various regions. North as Mosul, the Middle as Baghdad, the South as Basra, the South-West as Nasiriyah, the East as Kirkuk, South-East as Kut. Secondly, the showing results indicate the Models between the satellite databases and the earth databases stations besides giving very good correlations. Thus, this makes able to depend on the databases of the satellite stations to support the researchers with the necessary missing information of earth stations database. The founded limitations in this study are formulated in the researchers who are facing different difficulties of obtaining climatic datasets from earth stations.

This study noted certain disadvantages which are represented in the lack and missing data from the Earth stations because of finance lack of the staff at the Meteorological Earth stations, and the nature conditions. It is possible to eliminating them in future through using the Satellite climatic database of the certain missing or lack of Earth stations database information of the same time period, because the highly significant correlations between the estimated and measured results.

It is one of the most essential matters to utilize a direct and easy way to exchange information from different stations in order to develop this current research by means of supporting the researchers with required satellite databases, reducing the costs of obtaining it as well as making easy and fast reaching the information. The confronting difficulties, which face researcher, are formulated in the Mathematical and Statistical methods, which are used and tend to show highly significant correlations between the estimated and measured results.

\section{Conclusions}

A variety of Regression Models between (T ECMWF, RH ECMWF, WS ECMWF) and (T stat, RH stat, WS stat) have been performed in six stations well distributed in Iraq.

For air temperature a highly acceptable Correlations was obtained between (TECMWF\&T stat), in all stations where $R^{2}$ for these Models ranged between (0.996-0.999).

In all the Models the MAE ranged between (0.74-6.94) \% and RMSE ranged between (9.63-14.01) \%.

For relative humidity in all stations the $R^{2}$ of these Models ranged between (0.967-0.997). The MAE for these Correlations ranged between (3.66-8.39) \% while the RMSE ranged between $(6.78-12.2) \%$.

For wind speed Linear Model gave the best fit in Mosul, Kirkuk and Kut stations where $R^{2}$ equal $(0.848,0.752,0.996)$, while in Baghdad station Quadratic Model gave the best fit where $R^{2}$ equal (0.903). Logarithmic Models gave the best fit in Nasiriyah and Basrah where $R^{2}$ ranged between (0.924-0.925). The MAE in all stations ranged between (3.37-30.36) \%, while the RMSE ranged between (5.16-44.9) \%. 


\section{References}

[1] Flaieeh, H. K. (2009). The use of satellites for monitoring and forecasting of air. Journal of Research Diyala humanity, 34 , 454-478. Available at: https://www.iasj.net/iasj/download/19e0fde3abed86e7

[2] ERA5: data documentation. Available at: https://confluence.ecmwf.int/display/CKB/ERA5\%3A+data+documentation

[3] Al-Timimi, Y. K., Al-Salihi, A. M., Al-lami, A. M. (2014). Estimation of Land Surface Temperature for Different Regions in Iraq Using Remote Sensing Technique (ETM+). Engineering and Technology Journal, 32 (6), 1084-1091. Available at: https://www.researchgate.net/publication/280024382_Estimation_of_Land_Surface_Temperature_for_Different_Regions in_Iraq_Using_Remote_Sensing_Technique_ETM

[4] Fotsing Talla, C., Njomo, D., Cornet, C., Dubuisson, P., Akana Nguimdo, L. (2018). ECMWF Atmospheric Profiles in Maroua, Cameroon: Analysis and Overview of the Simulation of Downward Global Solar Radiation. Atmosphere, 9 (2), 44. doi: https://doi.org/10.3390/atmos9020044

[5] Noh, Y.-C., Sohn, B.-J., Kim, Y., Joo, S., Bell, W. (2016). Evaluation of Temperature and Humidity Profiles of Unified Model and ECMWF Analyses Using GRUAN Radiosonde Observations. Atmosphere, 7 (7), 94. doi: https://doi.org/10.3390/ atmos 7070094

[6] Cano, D., Monget, J. M., Albuisson, M., Guillard, H., Regas, N., Wald, L. (1986). A method for the determination of the global solar radiation from meteorological satellite data. Solar Energy, 37 (1), 31-39. doi: https://doi.org/10.1016/0038-092x(86)90104-0

[7] Lakshmi, V., Susskind, J. (2000). Comparison of TOVS-derived land surface variables with ground observations. Journal of Geophysical Research: Atmospheres, 105 (D2), 2179-2190. doi: https://doi.org/10.1029/1999jd900921

[8] Sugita, M., Brutsaert, W. (1993). Comparison of land surface temperatures derived from satellite observations with ground truth during FIFE. International Journal of Remote Sensing, 14 (9), 1659-1676. doi: https://doi.org/10.1080/01431169308953993

[9] Snyder, W. C., Wan, Z. (1996). Surface temperature correction for active infrared reflectance measurements of natural materials. Applied Optics, 35 (13), 2216. doi: https://doi.org/10.1364/ao.35.002216

[10] Akinnubi, R. T., Akinwale, B. F., Ojo, M. O., Ijila, P. O., Alabi, O. O. (2007). Characteristic variation of relative humidity and solar radiation over a tropical station Ibadan, Nigeria. Research Journal of Applied Sciences, 2 (12), 1266-1269.

[11] Khaleed, O. L. (2018). Analysis of seasonal pressure levels over Middle East using ECMWF data. Journal of College of Education for Pure Sciences, 8 (2). doi: https://doi.org/10.13140/RG.2.2.33262.36164

How to cite: A. Basheer, R., AL-Rijabo, Dr. W. I. (2021). Comparison between some meteorological elements measured by ECMWF and Earth stations in different regions in Iraq. EUREKA: Physics and Engineering, 4, 41-49. doi: https://doi.org/ 10.21303/2461-4262.2021.001941 